Review

\title{
Cannabinoids: from pot to lab
}

\author{
Esther Papaseit ${ }^{1,2}$, Clara Pérez-Mañá1,2, Ana Pilar Pérez-Acevedo1,2, Olga Hladun¹,2, M. Carmen \\ Torres-Moreno ${ }^{1,2}$, Robert Muga ${ }^{2,3}$, Marta Torrens, 2,4, Magí Farré1,2凶 \\ 1. Clinical Pharmacology Unit, Hospital Universitari Germans Trias i Pujol (HUGTP-IGTP), Badalona (Spain). \\ 2. Universitat Autònoma de Barcelona (UAB), Cerdanyola del Vallès, Barcelona (Spain). \\ 3. Internal Medicine Department, Universitari Germans Trias i Pujol (HUGTP-IGTP), Badalona (Spain). \\ 4. Drug Addiction Program, Institut de Neuropsiquiatria i Adiccions (INAD), Parc de Salut Mar, Barcelona (Spain). \\ $\square$ Corresponding author: Magí Farré. Clinical Pharmacology Unit, Hospital Universitari Germans Trias i Pujol, Carretera de Canyet, s/n. 08916 Badalona. \\ Spain. Phone. +34 93 4978865, +34 93 4651200; email: mfarre.germanstrias@gencat.cat. \\ (c) Ivyspring International Publisher. This is an open access article distributed under the terms of the Creative Commons Attribution (CC BY-NC) license \\ (https://creativecommons.org/licenses/by-nc/4.0/). See http://ivyspring.com/terms for full terms and conditions.
}

Received: 2018.05.05; Accepted: 2018.06.30; Published: 2018.08.06

\begin{abstract}
Cannabis is becoming increasingly present in our society. In recent years, the line between the natural (cannabis) and the synthetic (synthetic cannabinoids), the recreational (cannabis) and the medical (pharmaceutical cannabinoids and medical cannabis) has been crossed. In this paper we review some of the novel aspects of cannabis and cannabinoids in relation to their legal situation, changes in their composition and forms of cannabis use, the concept of medical cannabis, and synthetic cannabinoids as new psychoactive substances (NPS). We have also analyzed serious adverse reactions and intoxications associated with the use of synthetic cannabinoids, as well as the latest developments in the research of pharmaceutical cannabinoids.
\end{abstract}

Key words: Cannabis, Delta-9-tetrahydrocannabinol (THC), Cannabidiol (CBD), Medical cannabis; Synthetic cannabinoid

\section{Introduction}

In number of users, cannabis is the first illegal drug, and the third one if tobacco and alcohol are taken into account. Cannabis is increasingly present in our society both for its recreational (natural cannabis and synthetic cannabinoids) and medical use (pharmaceutical cannabinoids and medical cannabis). In 2015, an estimated 183.3 million people aged 15-64 years used cannabis (3.8\% of global population) [1]. Cannabis use is most prevalent among young people ages 15 to 34 (13.9\% using in the past year)[2]. Among 15 to 16 year-old school students in Europe and United States last month cannabis use was $8 \%$ and $15 \%$, respectively [3].

In recent years, natural preparations with user-tailored compositions and new synthetic cannabinoids with high pharmacological potency have appeared. The line between the natural and the synthetic has been crossed. In this paper we review some of the novel aspects of cannabis and cannabinoids in relation to their legal situation, changes in their composition and forms of use, the concept medical cannabis, the synthetic cannabinoids as new psychoactive substances (NPS) and the serious adverse reactions and intoxications after their use.

\section{Cannabis}

\subsection{Use of cannabis and its derivatives: legal aspects}

The legal status of cannabis continues to be highly controversial. Cannabis, its resin, extracts and tinctures are included in the I and IV United Nations Schedules of the 1961 Single Convention on Narcotic Drugs, and therefore they are subject to international control. Delta-9-tetrahydrocannabinol (THC) (isomers and stereochemical variants) and dronabinol (synthetic THC) are classified as psychotropic substances according to annexes I and II of the 1971 United Nations Convention on Psychotropic Substances, respectively [4, 5]. Despite its classification, control measures differ between countries in terms of the importance of possession and 
consumption offences and, consequently, in the application of administrative sanctions and/or penalties. Thus, in countries like the United States of America (USA) legal medical cannabis use is spreading in many states (29 states and districts) and recreational use is already allowed in seven of them (Alaska, California, Colorado, Maine, Massachusetts, Oregon, Washington, and Washington, D.C.). In Canada, cannabis is legal in only for medicinal purposes from early 2018, and on October 17, 2018, cannabis will be legal for recreational use [6]. In Europe, unlike the USA, the therapeutic use of cannabis is only legal in the Netherlands, Germany and Italy [7], although there are initiatives for approval in other countries. In South America, medical cannabis is legal in Uruguay and there are initiatives to legalize it in Argentina, among other countries.

In Spain, the Organic Law 4/2015 of March 30th on the Protection of Citizen Security on cannabis cultivation is in force since July $1^{\text {st, }} 2015$. Pursuant to article 36 , only cannabis consumption is considered a serious, punishable offence when committed in places visible to the public [8]. In response to this situation, cannabis social clubs (associations conceived as non-governmental organizations for the production and distribution of cannabis and its derivatives for recreational and/or medical purposes) are so far the legal alternative to growing on private property for personal consumption. Currently in Spain, under this definition, there are hundreds of cannabis social clubs distributed throughout the state and many others in process of formation [9]. In 2015, the Constitutional Court suspended the regional law that regulated the consumption and supply of these clubs in Navarre. The Government lodged a constitutional challenge against it because it was considered to invade state competences on penal legislation, public security and health. Recently, in Catalonia, a new Popular Legislative Initiative law has been approved. It regulates cannabis consumer organizations, as well as the cultivation and transportation of cannabis by these clubs. In Spain and some of its autonomous communities, the processes to legalize the therapeutic use of cannabis have also been initiated [10].

Among health care professionals who attend addictions, there is $40 \%$ who support the decriminalization of cannabis for personal use and/or its commercialization [11].

\subsection{Principal components of cannabis}

Cannabis is a flowering plant that contains more than 500 different chemical compounds, including hundreds of different cannabinoids and non-cannabinoids substances.
Non-cannabinoids compounds include a wide variety of terpenes and flavonoids. Terpenes are fragrant oils identified as the source of flavor and fragrance in the cannabis plant. Terpens are lipophilic molecules with activity in cell membranes, neuronal and muscle ion channels, neurotransmitter receptors, G-protein coupled (odorant) receptors, second messenger systems and enzymes which could contribute synergistically with cannabinoids to produce therapeutic actions $[12,13]$ Flavonoids are essential pigments found primarily in the flowers, leaves, and stems which are implicated in the unique smell and flavor of a cannabis strain. Similarly to terpenes, they may exert certain pharmacological activity [13].

The main cannabinoids are tetrahydrocannabinol (THC), cannabidiol (CBD), cannabinol (CBN), cannabigerol (CBG), tetrahydrocannabivarin (THCV), cannabichromene $(\mathrm{CBC})$, and their respective acids [tetrahydrocannabinol acid (THCA), cannabidiol acid (CBDA), cannabigerol acid (CBGA), tetrahydrocannabivarin acid (THCVA), and delta-8 tetrahydrocannabinol (delta-8-THC), cannabidivarin (CBGV) and cannabinovarin (CBNV)] [14-16].

\subsubsection{Tetrahydrocannabinol (THC)}

The psychoactive effects of cannabis are mainly due to the presence of THC. THC binds to cannabinoid receptors $\mathrm{CB}_{1}$ and $\mathrm{CB}_{2}$, acting as a partial agonist. $\mathrm{CB}_{1}$ receptors are located in the central nervous system (cerebral cortex, hippocampus, basal ganglia and cerebellum), lungs, liver and kidneys. $\mathrm{CB}_{2}$ receptors are primarily found in immune and hematopoietic cells. Both CB1 and CB2 are G protein-coupled receptors that inhibit the synthesis of intracellular adenosine cyclic monophosphate (cAMP) and thus involved in the signaling of different metabolic pathways). The characteristic effects of cannabis on behavior, nociception and thermal sensitivity, mood regulation, appetite and sexual activity, as well as antitumor and antiemetic properties, among others, derive from this activation. THC is also the component responsible for the reinforcing and addictive properties of cannabis [17-19].

\subsubsection{Cannabidiol (CBD)}

CBD, unlike THC, does not exert direct action on receptors $C_{1}$ and $C_{2}$, responsible for psychoactive effects. CBD binds on $\mathrm{G}$ protein-coupled receptors (GPR55), serotonergic receptors (5HT-1a), opioids (mu and delta), and transient receptor potential channels [TRPV-vanilloid (TRPV1, TRPV2), TRPA-ankirin (TRPA1), TRPM-melastatin (TRPM-8), equilibrative nucleoside transporter (ENT), 
peroxisome proliferator-activated gamma receptor (PPAR-ү) [20].

CBD is mostly devoid of adverse psychoactive effects and abuse liability. CBD possesses anticonvulsant, analgesic, anti-anxiety, antiemetic, immunemodulating, anti-inflammatory, neuroprotective, and anti-tumorigenic properties [21]. CBD has been evaluated for the treatment of some mental disorders (anxiety, schizophrenia, addictions) or some types of epilepsy [22-24]. Early clinical results are promising in some treatment-resistant childhood epilepsies, which will have to be confirmed [22]. A CBD oral solution (Epidiolex ${ }^{\circledR}$ ) has been approved by the US Food and Drug Administration in June 2018 for the treatment of seizures associated with two rare forms of childhood epilepsy (Lennox-Gastaut syndrome and Dravet syndrome) in patients 2 years of age and old.

\subsubsection{Cannabis/THC ratio}

The content or percentage (\%) of THC and its ratio to cannabidiol (CBD) or THC/CBD ratio defines the cannabis potency and its psychoactive effects. High THC/CBD ratios are associated with euphoric, relaxing, and anxiolytic effects, while low THC/CBD ratios often exert sedative effects and are used as medical cannabis.

\subsection{Changes in the composition of cannabis}

Cannabis in the illegal market is sold as cannabis inflorescences (marijuana, seedless, and ditch weed). Sativa variety presents the highest percentage of THC, indica and ruderalis varieties have the higher percentage of CBD. Some hybrid varieties present high potency such as the Skunk (75\% sativa, 25\% indica), cannabis resin (hashish, grifa) and liquid cannabis (oil or cannabis tea). According to the latest European Drug Report on the analysis of seizure data (2006-2014), there has been a considerable increase in potency of the herb (8-12\% THC) and resin (12-18\% THC) [24]. These observations coincide with the analysis carried out by the Drug Enforcement Administration (DEA), with an increase in the percentage of THC from 4 to $12 \%$ in the last 20 years [25]. Similar increases in potency have also been documented in Australia and the Netherlands [26, 27]. This global trend has been mainly attributed to the selection and introduction of variants with a high content of THC and the use of intensive production techniques [28]. In this regard, several studies have associated cannabis use with a high percentage of THC (herb or THC extracts) with a considerable increase in acute toxicity, and especially with an increased risk of psychosis [15, 29-34]. It is important to note, as discussed later in the section of medical cannabis, that, for some years, cannabis products of different percentage composition of THC and CBD have been commercialized, so that one can get the desired THC and CBD percentage and adjust it to one's preferences or needs, especially for medicinal use. This includes seeds that guarantee adjusted content.

\subsection{New forms of cannabis use: electronic cigarettes, vaporizers}

Since ancient times cannabis has been used orally as solid (cannabis butter,"majoun", brownies, cookies or cakes) and liquid products (infusions and teas, "bhang", "charas", "ganja", dyes or oils). The main method of consumption is pulmonary inhalation [joints, blunts, pipes (whether made of wood; metal "cachimba", "shisha", hookah; water or bong)]. Recently, in the US and Europe a new form of use popularly known as "dabbing" has been established, which consists of extracting a sticky oil with a high content of THC (higher than 70\%) (honey, dabs, wax, shater) using butane gas [butane hash oil (BHO)] through a specially designed dab rig device (nail, torch, carb cab and mat). In recent years, apart from "dabbing", other new forms of cannabis use have been spread by means of electronic devices: modified electronic cigarettes (e-cigarettes) and vaporizers [35]. "Cannavaping" refers to the inhalation of smoke through electronic cigarettes that are capable of vaporizing THC-enriched e-liquids or other models designed exclusively for THC use (e.g. "e-joint") or only CBD (KanaVape®) [27]. There is also a wide variety of vaporizers, either portable, desktop or electrical. The latter are more complex devices (base, filling chamber, valves, bag, nozzle) which vaporize through hot air at an adjustable temperature. Finally,

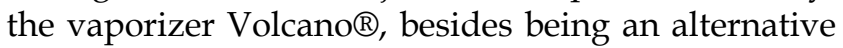
to the methods of recreational consumption of THC, it is the only one approved as a medical device in the European Union (EU) and Canada [36, 37]

\subsection{Therapeutic use of cannabis: medical cannabis}

Medical cannabis (or medicinal marijuana) is a broad term that encompasses the use of cannabis for therapeutic purposes. As such, it includes products of medical cannabis and the medication of natural origin Sativex ${ }^{\circledR}$ that will be reviewed in this section. Synthetic cannabinoids approved as drugs by competent regulatory agencies (Marinol® or Cesamet $($ ) will be reviewed in section 3.3. Therapeutic use of synthetic cannabinoids.

In the Netherlands, cannabis can be purchased as different pharmaceutical preparations of cannabis flowers standardized on THC and CBD named "Cannabis flos" (sativa variety: Bediol ${ }^{\circledR}[6.5 \%$ THC, 
$8 \%$ CBD-granules], Bedrobinol ${ }^{\circledR}[13.5 \%$ THC, $<1 \%$ CBD], Bedrocan ${ }^{\circledR}[22 \%$ THC, $<1 \%$ CBD]; indica variety: Bedica ${ }^{\circledR}[14 \%$ THC, $<1 \%$ CBD $]$, Bedrolite ${ }^{\circledR}$ $\left[0.4 \%\right.$ THC and $9 \%$ CBD], Bedropuur ${ }^{\circledR}$ [high THC \%, $<1 \%$ CBD available for research]) [38].

In Canada, besides cannabis flowers standardized on THC and CBD (0.7-22\% THC, $0.5-13 \%$ CBD), they also have cannabis oils with different concentrations (1-18.3\% THC, $0.2-20 \%$ CBD) [39].

In Italy, from January 2017, the Government has put on sale standardized cannabis preparations (inflorescences for smoking or preparing tea or oil) produced by the Military Pharmaceutical Institute in Florence. This medicinal sativa variety of cannabis, called FM2 (Pharmaceutical, Military and 2 cannabinoids) or also known as "cannabis di stato" or "cannabis italiana", has a THC and CBD percentage varying between $5-8 \%$ and $7-12 \%$, respectively, with a cannabinoid profile similar to the Dutch preparation Bediol ${ }^{\circledR}$ and a significantly lower market price [40].

On the other hand, the term "medical cannabis" coexists with "legal medical marijuana" or "medical marijuana", defined as the use of the unprocessed plant itself (cannabis sativa) or an extract of it to treat symptoms or an illness. In the USA, the medicinal use of marijuana is permitted for patients with serious medical conditions, including dozens of pathologies and symptoms, ranging from anxiety to insomnia, attention deficit hyperactivity disorder (ADHD), depression, arthritis and anorexia, among others. It can only be prescribed in the form of capsules, liquids and/or oils to vaporize, inhale and/or administer orally (infusions, tinctures, candy, cakes, cookies, among others) or topically (patches, creams). Some of the most important companies in this sector are BinduBotanicals, CW Botanicals, Royal Queen Seeds, and BioCBD+, among others. Specifically, CW Botanicals and Royal Queen Seeds have an entire plant extract of the Charlotte's variety based on CBD for the treatment of epilepsy and a $4 \%$ CBD oil $(0.2 \%$ THC), respectively $[41,42]$, while BioCBDplus markets a combination of $\mathrm{CBD}$ and turmeric with anti-inflammatory effects used by athletes and also by patients with rheumatoid arthritis and autoimmune diseases [43]. It should be noted that in the US, medical cannabis preparations are marketed in multiple forms, sometimes resembling high consumption food products (lollypops). In relation to dietary supplements, the Food and Drug Administration (FDA) warns that no product containing CBD can be named as such, and expressly prohibits the addition of CBD in any type of food product [44]. It should be noted that, according to data published in the general press, in some USA states, the cannabis legal industry (medical and recreational) brings in more taxes than alcohol.

In 2005, Health Canada approved nabiximol, a pharmaceutical preparation that comes from selected cannabis plants and contains a 1:1 THC/CBD ratio (Sativex $\AA$ ). It was indicated for the treatment of moderate or severe spasticity in multiple sclerosis and was later extended to treatment of opioid-non-responsive pain in these patients. Sativex ${ }^{\circledR}$ is available in many other countries, within the EU: Spain, France, and the United Kingdom (UK), among others.

\section{Synthetic cannabinoids (SCs)}

\subsection{Origin and recreational use}

SCs also called cannabimetics, are a large and heterogeneous group of substances that are characterized by its acting on the same brain receptors as THC, and they constitute the largest group of new psychoactive substances (NPS) [1,2]. According to the United Nations Office on Drugs and Crime (UNODC), out of the 739 analyzed NPS in 2016, the majority of them were SCs (32\%) [45]. From 2008 to 2016 the EU Early Warning System has identified 169 new SCs (1 in 2008, 9 in 2009; 11 in 2010, 23 in 2011, 30 in 2012; 29 in 2013; 30 in 2014; 25 in 2015 and 11 in 2016). At the same time, there has been an increase in seizures [2].

The first SCs were synthesized 25 years ago by academic laboratories or the pharmaceutical industry. Indeed, some of the names of these SCs come from the name of the person responsible for its synthesis, for example, John W. Huffman, from Clemson University in the USA. Subsequently, the names of many others have also been granted depending on the person/institution that synthesized them, for example, in the case of AM-2201 (Alexandros Makriyannis), HU-210 (Hebrew University), CP 47,497 (Charles Pfizer) or WIN 55,212-2 (Sterling Winthrop, Inc.).

Currently SCs are classified according to their chemical structure in seven groups: naphthoylindoles, naphthylmethylindoles, naphthoylpyrroles, naphthylmethylindenes, phenylacetylindoles, cyclohexylphenols, and dibenzopyrans or classical cannabinoids. However, the progressive identification of SCs of new synthesis has led to the use of new terms and classifications. In recent years, in many publications, SCs are referred to as synthetic cannabinoid receptor agonists (SCRA), in reference to their action as agonists or partial agonists on cannabinoid receptors, although there may be other mechanisms of action (e.g. the inhibition of enzymes that degrade natural cannabinoids). Consumption 
bans since 2009 [46, 47] and the Controlled Substance Act (2012) have led to successive structural changes and, consequently, to the classification of SCRA into first (JHW-018), second (AM-2201, UR-1448) and third generation (BB-22, 5F-PB-22, 5F-AKB-48 and STS-135), respectively. Later, other $\mathrm{SCs}$ appeared, such as APINACA, MDMB-FUBINACA, ADB-FUBINACA, MDMB-CHMICA, AB-CHMINACA and 5F-MDMBPINACA, UR-144, 5F-AKB48, and ADB-CHMINAC. In Europe, the five SCs that were seized the most in 2015 were ADB-FUBINACA, AB-CHMINACA, R-144, 5F-AKB48 and ADB-CHMINACA [2].

According to 2015 data published by the European Monitoring Centre for Drugs and Drug Addiction (EMCDDA), approximately $64 \%$ of the seized SCs was in the form of herbal mixtures and $13 \%$ in the form of processed powders in "smokable herbal mixtures" [2]. As epidemiological studies and survey data from recreational consumers show, SCs can be purchased in the form of powder, oily paste, herbal mixture or incense [48]. The powder is normally white but it can be of other colors. It tends to be packed in bags with labels that provide information about the composition, weight and purity, which specify that the content is "not suitable for human consumption", "for laboratory use only", "for technical use only". However, the most common form of presentation for SCs are preparations in the form of herbs, which are normally sold in packages of striking appearance that typically contain 0.4-3 grams of dried vegetable matter (different plant species with psychoactive effects) to which are added one or more SCs. This composition can vary even between different packages of the same product. Most packages include the warning that this is "a mixture of incense" that releases various scents (activity/workout sessions: aromatherapy, yoga, or meditation) and that, as well as packages that include powder, they are not suitable for human consumption. Most of them are marketed under trade names such as Spice, K2, Puff, Kronic, Karma, Voodoo, Kaos, Yucatan Fire, Smoke, Sence, Chill X, Highdi'sAlmdröhner, Earth Impact, Gorillaz, Skunk, Genie, Galaxy Gold, Space Truckin', Solar Flare, Moon Rocks, Blue Lotus, Aroma or Scope [49].

In Europe, the popular SC phenomenon has been partly due to the high demand for cannabis, as well as the continuous emergence onto the market of new SCs when the existing ones were subject to control measures.

\subsection{Pharmacology and clinical pharmacology of synthetic cannabinoids}

Generally, the available information on the pharmacology of SCs is limited. However, there is data in which they were studied as potential drugs. In the market, there is a lot of SCs of different compositions and varieties and there is even presence of several different SCs within the same product [50, 51]. Currently, available data are derived from "in vitro" and "in vivo" preclinical studies, in particular from JWH-018 and WIN55,212-2, CP55,940 and HU-210 [52]. First generation SCs, as JWH-018, are CB1 and CB2 agonists with a higher affinity than THC and showed CB1-dependent reinforcing properties and dopamine (DA) stimulant actions [53]. Third SCs generation (BB-22, 5F-PB-22, 5F-AKB-48 and STS-135) can be even more potent as a CB1 receptor agonists compared to JWH-018 [54].

Overall, SCs are mainly pure agonists for $\mathrm{CB}_{1}$ and $\mathrm{CB}_{2}$ receptors, and less frequently, partial agonists or antagonist. In addition, it has been proved that some of them such as WIN55,212-2, CP55,940 and HU-210 may also be involved in the modulation of GABAA, mu-opioid, serotonergic $\left(5-\mathrm{HT}_{2 \mathrm{~A}}\right)$ and dopaminergic receptors. In animal models, the acute administration of THC and SCs typically produces hypothermia, analgesia, cataplexy and reduced locomotive activity, as well as hypotension due to their activity on $\mathrm{CB}_{1}$. Anti-inflammatory, antiproliferative and antioxidant properties are attributed to $\mathrm{CB}_{2}[55,56]$. Regarding chronic effects and, especially, tolerance, they vary depending on the SC administered, age, dose, route of administration, and duration of exposure. Based on all these factors, the repeated administration of some SCs has been linked to deficits in short-term and working memory, as well as alterations in the process of discrimination and implication of anxious states and the response to stress [57].

As for the vast majority of NPS, there are no clinical trials specifically designed to evaluate their human pharmacology. At least there has been published a dozen studies that included "semiexperimental" administration (self-administration) of one or more SCs for their detection and quantification in order to validate analytical methods. In some of these studies, plasma and/or urinary concentrations and, occasionally, subjective effects have been described. This is the case for Spice2, Smoke, K2 Standard, K2 Citron, Summit, AM-694, AB-001 and AM2201, JWH-018, and JWH-073 [58-64]. Peak plasma concentrations were reached approximately 10 minutes after intrapulmonary administration (smoked), the main effects for all of them being increased heart rate, dry mouth, eye redness and alterations in mood and perception, similar to what was observed after the experimental administration of THC. The first pharmacokinetic, neurocognitive and subjective data on JWH-018 in humans have been 
recently published $[65,66]$. Despite the limitations of the study (small sample $(n=6)$ and lower doses than those used for recreational purposes) the results suggest similar pharmacokinetics to THC. The study analyses $2 \mathrm{~g}$ and $3 \mathrm{~g}$ of $\mathrm{JWH}-018$ smoked in a pipe and for both doses mean peak plasma concentrations were reached approximately 5 minutes after administration [65].

\subsection{Therapeutic use of synthetic cannabinoids}

Despite the fact that since ancient times the medicinal properties of cannabis and its use in numerous ailments have been widely documented, it wasn't included as such in the American and European pharmacopoeia until the end of the 19th century. It was illegalized by the International Opium Convention of 1925 and the Marijuana Tax Act of 1937. Even though they were not specifically enacted to criminalize its medicinal use, it negatively affected its use in medical terms. Several decades later, in 1964, the chemical structure of THC was discovered and synthesized for the first time (Professor Raphael Mechoulam, Hebrew University of Jerusalem) [67]. Thereafter, and coinciding with its progressive decriminalization, the interest for its potential therapeutic effects resurged. In the 90 's, the discovery of several compounds: anandamide ( $\mathrm{N}$-arachidonoylethanolamine or AEA), 2-arachidonoylglycerol (2-AG), arachidonic acid and its derivatives gave a name to the endocannabinoid system. Its involvement in the analgesia, cognition, and memory processes/pathways, locomotive activity, appetite, vomiting and immune function significantly increased biomedical research and the therapeutic potential of cannabis. However, it was not until 1985 that the FDA approved the first cannabinoid drug-dronabinol (synthetic THC, Marinol ${ }^{\circledR}$ ) and nabilone (a synthetic THC, Cesamet ${ }^{\circledR}$ ) for the nausea and vomiting caused by chemotherapy as side effects in patients refractory to other antiemetic treatments. Later, in 1992, the indication of dronabinol was extended to the treatment of patients suffering from HIV-associated anorexia. Further on, other drug regulatory authorities approved the commercialization of other cannabinoid drugs. As mentioned, in 2006, the natural preparation Sativex ${ }^{\circledR}$ and rimonabant (Acomplia $\left.{ }^{\circledR}\right)$ were approved in Canada by the European Medicine Agency (EMA). Rimonabant was the first cannabinoid indicated in patients with overweight and obesity for reducing appetite but it was taken off the market in 2009, after detecting a significant increase in the risk of mental disorders, and the notification of five cases of suicide [68]. Currently, commercialized cannabinoid drugs differ depending on the country. In the UK and the
USA, dronabinol and nabilone, while nabiximols can be prescribed in many countries of the European Union, and in Canada, as already mentioned [69, 71].

In the past 10 years, different cannabinoids have been investigated in preclinical studies and even in advanced stages of clinical studies [Otenabant ${ }^{\circledR}$ (CP-945,598) and Taranabant ${ }^{\circledR}$ (MK-0364), both similar to rimonabant, levonantradol (Nantrodolum ${ }^{\circledR}$ ), andajulemic acid (AJA; CT3)]. However, due to the lack of efficacy and/or toxicity, finally none of them has been approved for human use.

Other potentially effective cannabinoids for the treatment of different diseases are currently under research/approval. Echopharma is developing Namisol@ (98\% pure, natural THC) for multiple sclerosis, Alzheimer's disease and chronic pain [72, 73]. GW Pharmaceuticals has Epidiolex (C) (98\% CBD), which has been already classified by the FDA as an orphan drug for Lennox-Gastaut and Dravet syndromes (severe myoclonic epilepsy of infancy, or polymorphous epilepsy) and tuberous sclerosis [21, 69, 74].Different molecules in the process of development have also fallen into the same category: i) GWP42006 [Cannabidivarin (CBDV)] for epilepsy; ii) GWP 42002 for glioma; iii) GWP42003 for neonatal hypoxic-ischemic encephalopathy, schizophrenia and glioma; iv) GWP42004 for diabetes type 2 [75]. The potential therapeutic effect of CBD is also being evaluated for the treatment of Parkinson's disease, anxiety disorder, multiple sclerosis, substance use disorder, post-traumatic stress disorder, graft-versus-host disease, among others [16, 21, 22, 76]. In addition, they are also being studied in several neurodegenerative, psychiatric, oncological, ophthalmological and dermatological diseases, among others [77].

\subsection{Adverse reactions and intoxications caused by synthetic cannabinoids}

3.4.1. Adverse reactions and intoxications caused by the recreational use of synthetic cannabinoids

Information about adverse reactions and intoxications associated with the consumption of SCs is limited mainly because it is difficult to find biological matrices in acute care areas (currently there are no commercial fast diagnostic kits) and because of the constant emergence of new SCs. Even so, the general toxicity profile of SCs is presumably similar to high-potency cannabis characterized by more potent and long-lasting effects [50].

In this regard, there are epidemiological and toxicological data coming from surveys, poison centers, intoxication registers, clinical cases and case series. Data reported suggest that severe adverse 
reactions and fatal intoxications are much more common with SCs than with cannabis probably linked to high potency and the unintentionally high doses used $[50,51,83,84]$.

According to notifications received by American poison centers, adverse reactions associated with the use of SCs increased by $330 \%$ in early 2015 (January-April), the most frequently reported symptoms being agitation, nausea, tachycardia, drowsiness/lethargy, vomiting and confusion [78]. These data coincide with cases of acute poisoning in patients seen in the Emergency department, who typically have psychiatric (agitation, anxiety, panic attacks, psychotic symptoms, hallucinations), cardiovascular (tachycardia, hypertension and chest pain), gastrointestinal (nausea, vomiting) and neurological symptoms (decreased level of consciousness) [79-82]. Most of them are quickly solved (6-24 hours) with symptomatic medical treatment. However, among serious and life-threatening complications, the following have been described: myocardial infarction, transient ischemic attack, acute kidney injury, generalized tonic-clonic seizures, psychosis, and suicidal ideation.

SCs in comparison to cannabis have been described have high-risk of developing psychosis especially in young individuals $[50,51,83,84]$. At this respect, findings from brain imaging studies suggest that SC could produce alterations/changes in brain regions that are often implicated in psychosis [50]. Importantly, evidence indicates that SCs use impairs executive functions $[51,85]$.

The SCs that were detected the most in cases of acute poisoning correspond to derivatives of JWH, and to a lesser extent, of XRL-11, ADB-PINACA, AM-2201， MAM-2201，5F-PB-22， UR-144， PB-22, AM-2233, AM-694, NNEI, BB-22, CP-47, 497-C8 and 5F-ADB. In addition to outbreaks occurred in Europe, clinical patterns affecting dozens of SC users have been recently described in areas of American cities like New York [86].

In the latest and largest online survey about drug use [Global Drug Survey (GDS)], 12.5\% of daily and weekly SC users have required urgent medical treatment (3.5\% of respondents), posing a 30-fold higher risk compared to cannabis users. According to these data, more than half of daily and weekly SC users talk about withdrawal, which is described as being similar to the one from cannabis [87-89]. Based on the available limited evidence, it is suggested that SCs, in comparison with cannabis, have greater cardiac and neurological toxicity.

The EMCDDA due to the reported high toxicity of some SCs, has issued several warnings on the subject. In the last one, published in February 2016, the SC MDMB-CHMICA has been linked to 13 deaths and 23 non-fatal intoxications [90-95].

\subsubsection{Adverse reactions and intoxications caused by a synthetic cannabinoids in clinical development: the BIA 10-2474 case}

Severe adverse reactions of currently marketed pharmaceutical cannabinoids have not been recorded. The adverse reactions most often described are mild to moderate, with dizziness, fatigue, ataxia, and difficulty concentrating.

However, in 2016, the emergence of several very serious adverse reactions was reported following the experimental administration of a cannabinoid drug in phase I study in Rennes (France). Subsequently, it was known that it was caused by BIA 10-2474 (Bial Pharmaceutical ${ }^{\circledR}$, Portugal), which is an inhibitor of fatty acid amide hydrolase (FAAH) that increases the concentration of anandamide in the central nervous system and peripheral tissues. Previously, this drug had been administered in a single dose $(0.25-10 \mathrm{mg})$ and multiple doses (2.5 - $10 \mathrm{mg} /$ day for 10 days) to successive cohorts of up to 84 volunteers without observing adverse reactions. Between the 5-7th day of administration of $50 \mathrm{mg} /$ day $(\mathrm{n}=6), 4$ volunteers had clinical neurological manifestations such as headache, cerebellar ataxia, memory impairment, altered level of consciousness, diplopia, hemiparesis and amnesia. Brain death was observed in one of them, two recovered with sequelae (one subject with residual memory impairment, and the other one with residual cerebellar syndrome), and one recovered without sequelae. The nuclear magnetic resonance imaging study revealed irreversible brain damage, hemorrhage and necrosis [96]. According to the research carried out, it has been suggested that several factors might have contributed to the dramatic event, such as low drug specificity and reversibility (high inhibition), impact on the immune system, dose calculation, cumulative toxicity, off-target effects, drug impurities, and human error [97]. Currently, the mechanisms involved in the neurotoxicity of BIA 10-2474 are unknown exactly, but experimental studies are trying to elucidate the possible etiology [98-99]. A recent paper in human cells using an activity-based protein profiling, suggests that BIA 10-2474, besides acting as an irreversible FAAH inhibitor, could alter neuronal lipid metabolism by inhibition of PNPLA6, an off-target protein. It is known from in vitro studies that the drug inhibits $50 \%$ of FAAH activity at the dose of $0.25 \mathrm{mg}$, and $100 \%$ at the dose of $5 \mathrm{mg}$, and seems less selective than other inhibitors in development. Although, right now, there is no causal relationship and there are many unknowns to be solved, it has been postulated that the 
risk of cerebral toxicity could depend on the biological species being studied. This is the reason why toxicity was not observed in preclinical studies performed in rats and mice [100].

The FDA, in collaboration with the EMA and the French National Agency for Medicines and Health Products Safety (Agence Nationale de Sécurité du Médicament et des Produits de Santé, ANSM), has issued a note clarifying that the toxicity presented by BIA 10-2474 cannot be extended to other FAAH inhibitor drugs that are in experimental phase [101]. There are currently several laboratories that are investigating in the same vein. Right now, there isn't any marketed endocannabinoid drug acting specifically through this pathway.

\section{Conclusions}

The use of cannabis and, in general, cannabinoids has spread in recent years. It should be noted that the synthetic cannabinoids and the medical cannabis phenomena have opened the debate on their legalization in recreational and, especially, medical terms. To this day, both aspects continue to be a topic of great interest in public health and clinical medicine.

\section{Acknowledgements}

This work was supported by the following projects (Instituto de Salud Carlos III-ISCIII, Proyectos de Investigación en Salud PI14/00715, Red de Trastornos Adictivos-RTA RD16/0017/0003, and RD16/0017/0010, Juan Rodés JR16/00020), integrated in the National R + D + I and funded by the ISCIII and the European Regional Development Fund (FEDER). In addition by grants from Ministerio de Sanidad, Política Social e Igualdad (Plan Nacional Sobre Drogas-PNSD, 2015I054), and Suport Grups de Recerca AGAUR-Gencat (2017 SGR 316 and 2017 SGR 530).

\section{Competing Interests}

The authors have declared that no competing interest exists.

\section{References}

1. UNDOC (United Nations Office on Drugs and Crime). World Drug Report 2017. https://www.unodc.org/wdr2017/index.html

2. EMCDDA (European Monitoring Centre for Drugs and Drug Addiction). European Drug Report 2017: Trends and Developments. http://www.emcdda.europa.eu/publications/edr/trends-development s/2017

3. EMCDDA (European Monitoring Centre for Drugs and Drug Addiction). Statistical Bulletin 2018. https://www.emcdda.europa.eu/ data/stats 2018

4. United Nations Office on Drugs and Crime (UNDOC). Convención Única de 1961 sobre Estupefacientes. https://www.unodc.org/pgl/ convention 1961_es.pgl.

5. United Nations Office on Drugs and Crime (UNDOC). Convenio sobre Sustancias Sicotrópicas de 1971. Recuperado de. https:// www.unodc.org/pgl/convention_1971_es.pgl.
6. Government of Canada. https://www.canada.ca/en/services/ policing/justice/legalization-regulation-marijuana.html)

7. Bifulco M, Pisanti S. Medicinal use of cannabis in Europe: the fact that more countries legalize the medicinal use of cannabis should not become an argument for unfettered and uncontrolled use. EMBO Rep. 2015; 16: 130-2.

8. Boletín Oficial del Estado (BOE). Ley Orgánica 4/2015, de 30 de marzo, de Protección de la Seguridad Ciudadana. https://www.boe.es/ buscar/pdf/2015/BOE-A-2015-3442-consolidado.pdf

9. Decorte T. Cannabis social clubs in Belgium: organizational strengths and weaknesses, and threats to the model. Int J Drug Policy. 2015; 26: 122-30.

10. Álvarez A, Gamella JF, Parra I. The legalization of cannabis derivatives in Spain: Hypothesis on a potential emerging market. Adicciones. 2017; 29: 195-206

11. Rossi P, Blay E, Costela V, et al. Illicit drug policy in Spain: the opinion of health and legal professionals. Adicciones. 2018; 30: 33-40.

12. Grof CPL. Cannabis, from plant to pill. Br J Clin Pharmacol. 2018; Apr 27.

13. Russo EB. Taming THC: potential cannabis synergy and phytocannabinoid-terpenoid entourage effects. Br J Pharmacol. 2011; 163: 1344-64.

14. Andre CM, Hausman JF, Guerriero G. Cannabis sativa: The Plant of the Thousand and One Molecules. Front Plant Sci. 2016; 7:19.

15. Casajuana Köguel C, López-Pelayo H, Balcells-Olivero MM, et al. Psychoactive constituents of cannabis and their clinical implications: a systematic review. Adicciones. 2018; 30: 140-151.

16. Fasinu PS, Phillips S, ElSohly MA, et al. Current Status and Prospects for Cannabidiol Preparations as New Therapeutic Agents. Pharmacotherapy. 2016; 36: 781-96.

17. De Luca MA, Di Chiara G, Cadoni C, et al. Cannabis; Epidemiological, Neurobiological and Psychopathological Issues: An Update. CNS Neurol Disord Drug Targets. 2017; 16: 598-609.

18. Russo EB, Marcu J. Cannabis Pharmacology: The Usual Suspects and a Few Promising Leads. Adv Pharmacol. 2017;80: 67-134.

19. Adams IB, Martin BR. Cannabis: pharmacology and toxicology in animals and humans. Addiction. 1996; 91: 1585-614.

20. Hanuš LO, Meyer SM, Muñoz E, et al. Phytocannabinoids: a unified critical inventory. Nat Prod Rep. 2016; 33: 1357-1392.

21. Perucca E. Cannabinoids in the Treatment of Epilepsy: Hard Evidence at Last? J Epilepsy Res. 2017; 7: 61-76.

22. Devinsky O, Cross JH, Laux L, et al. Trial of Cannabidiol for Drug-Resistant Seizures in the Dravet Syndrome. N Engl J Med. 2017; 376: 2011-2020.

23. Devinsky O, Marsh E, Friedman D, et al. Cannabidiol in patients with treatment-resistant epilepsy: an open-label interventional trial. Lancet Neurol. 2016; 15: 270-8.

24. Hussain SA, Zhou R, Jacobson C, Weng J, et al. Perceived efficacy of cannabidiol-enriched cannabis extracts for treatment of pediatric epilepsy: A potential role for infantile spasms and Lennox-Gastaut syndrome. Epilepsy Behav. 2015; 47: 138-41.

25. European Monitoring Centre for Drugs and Drug Addiction (EMCDDA). A cannabis reader: global issues and local experiences. Perspectives on cannabis controversies, treatment and regulation in Europe. https://archive.org/stream/CannabisMonograph8Vol1/ Cannabis_Monograph8_Vol1_djvu.txt

26. ElSohly MA, Mehmedic Z, Foster S, et al. Changes in Cannabis Potency Over the Last 2 Decades (1995-2014): Analysis of Current Data in the United States. Biol Psychiatry. 2016; 79: 613-9.

27. Swift W, Wong A, Li KM, Arnold JC, McGregor IS. Analysis of cannabis seizures in NSW, Australia: cannabis potency and cannabinoid profile. PLoS One. 2013; 8e70052.

28. Niesink RJ, Rigter S, Koeter MW, et al. Potency trends of $\Delta$ 9-tetrahydrocannabinol, cannabidiol and cannabinol in cannabis in the Netherlands: 2005-15. Addiction. 2015; 110: 1941-50.

29. EMCDDA (European Monitoring Centre for Drugs and Drug Addiction). European Drug Report 2016. http://www.emcdda .europa.eu/system/files/publications/2637/TDAT16001ENN.pdf

30. Barkus E. High-potency cannabis increases the risk of psychosis. Evid Based Ment Health. 2016; 19: 54.

31. Keller CJ, Chen EC, Brodsky K, et al. A case of butane hash oil (marijuana wax)-induced psychosis. Subst Abus. 2016 Jul-Sep;37: 384-386.

32. Di Forti M, Marconi A, Carra E, et al. Proportion of patients in south London with first-episode psychosis attributable to use of high potency cannabis: a case-control study. Lancet Psychiatry. 2015;2: 233-8.

33. Hall W, Degenhardt L. High potency cannabis: a risk factor for dependence, poor psychosocial outcomes, and psychosis. BMJ. 2015; 350:h1205. 
34. Murray RM, Quigley H, Quattrone D, Englund A, Di Forti M. Traditional marijuana, high-potency cannabis and synthetic cannabinoids: increasing risk for psychosis. World Psychiatry. 2016; 15: 195-204.

35. Pierre JM, Gandal M, Son M. Cannabis-induced psychosis associated with high potency "wax dabs". Schizophr Res. 2016; 172: 211-2.

36. Giroud C, de Cesare M, Berthet A, et al. E-Cigarettes: A Review of New Trends in Cannabis Use. Int J Environ Res Public Health. 2015; 12: 9988-10008.

37. Lanz C, Mattsson J, Soydaner U, Brenneisen R. Medicinal Cannabis: In Vitro Validation of Vaporizers for the Smoke-Free Inhalation of Cannabis. PLoS One. 2016; 11:e0147286.

38. Hazekamp A, Ruhaak R, Zuurman L, van Gerven J, Verpoorte R. Evaluation of a vaporizing device (Volcano) for the pulmonary administration of tetrahydrocannabinol. J Pharm Sci. 2006; 95: 1308-17.

39. Bedrocan Medicinal Cannabis. https://www.bedrocan.nl/

40. CanniMed - Canada's Medical Marijuana. https://www.cannimed.ca/

41. Pacifici R, Marchei E, Salvatore F, et al. Evaluation of long-term stability of cannabinoids in standardized preparations of cannabis flowering tops and cannabis oil by ultra-high-performance liquid chromatography tandem mass spectrometry. Clin Chem Lab Med. 2018; 56: 94-96.

42. CW botanicals. https://www.cwhemp.com/

43. Royal Queen Seeds. https://www.royalqueenseeds.com/

44. BioCBP+. https://www.biocbdplus.com/

45. Food and Drug Administration (FDA). FDA and Marijuana: Questions and Answers. http://www.fda.gov/NewsEvents/PublicHealthFocus/ ucm421168.htm\#dietarysuppl

46. United Nations Office on Drugs and Crime (UNDOC).(2017). Market analysis of synthetic drugs. Amphetamine-type stimulants, new psychoactive substances. Disponibleen. https://www.unodc.org/ wdr2017/field/Booklet_4_ATSNPS.pdf

47. Advisory Council on the Misuse of Drugs (ACMD).Cannabis classification and Public Health. https://www.gov.uk/government/ uploads/system/uploads/attachment_data/file/119149/acmd-report-a gonists.pdf

48. Controlled Substance Act. Synthetic Drug Abuse Prevention Act of 2012. https://www.gpo.gov/fdsys/pkg/BILLS-112s3190is/pdf/BILLS-112s3 190is.pdf

49. El portal de Energy Control. http://energycontrol.org/

50. Mustata C, Torrens M, Pardo R, Pérez C; Psychonaut Web Mapping Group, Farré M. [Spice drugs: cannabinoids as a new designer drugs]. Adicciones. 2009; 21: 181-6.

51. Weinstein AM, Rosca P, Fattore L, et al. Synthetic Cathinone and Cannabinoid Designer Drugs Pose a Major Risk for Public Health. Front Psychiatry. 2017; 8: 156

52. Fattore L. Synthetic Cannabinoids-Further Evidence Supporting the Relationship Between Cannabinoids and Psychosis. Biol Psychiatry. 2016; 79: 539-48.

53. Tai S, Fantegrossi WE. Synthetic Cannabinoids: Pharmacology, Behavioral Effects, and Abuse Potential. Curr Addict Rep. 2014;1:129-136

54. De Luca MA, Bimpisidis Z, Melis M, et al. Stimulation of in vivo dopamine transmission and intravenous self-administration in rats and mice by JWH-018, a Spice cannabinoid. Neuropharmacology. 2015; 99. 705-14.

55. De Luca MA, Castelli MP, Loi B, et al. Native CB1 receptor affinity,intrinsic activity and accumbens shell dopamine stimulant properties of third generation SPICE/K2 cannabinoids: BB-22, 5F-PB-22, 5F-AKB-48 and STS-135.Neuropharmacology. 2016; 105: 630-8.

56. Castaneto MS, Gorelick DA, Desrosiers NA, et al. Synthetic cannabinoids: epidemiology, pharmacodynamics, and clinical implications. Drug Alcohol Depend. 2014; 144: 12-41.

57. Mills B, Yepes A, Nugent K. Synthetic Cannabinoids. Am J Med Sci. 2015; 350: 59-62.

58. White CM. The Pharmacologic and Clinical Effects of Illicit Synthetic Cannabinoids. J Clin Pharmacol. 2017; 57: 297-304.

59. Auwärter V, Dresen S, Weinmann W, et al. 'Spice' and other herbal blends: harmless incense or cannabinoid designer drugs? J Mass Spectrom. 2009; 44: 832-7.

60. Hutter M, Moosmann B, Kneisel S, et al. Characteristics of the designer drug and synthetic cannabinoid receptor agonist AM-2201 regarding its chemistry and metabolism. J Mass Spectrom. 2013; 48: 885-94.

61. Grigoryev A, Kavanagh P, Melnik A. The detection of the urinary metabolites of 1-[(5-fluoropentyl)-1H-indol-3-yl]-(2-iodophenyl) methanone (AM-694), a high affinity cannabimimetic, by gas chromatography - mass spectrometry. Drug Test Anal. 2013; 5: 110-5.

62. Grigoryev A, Kavanagh P, Melnik A. The detection of the urinary metabolites of 3-[(adamantan-1-yl)carbonyl]-1-pentylindole (AB-001), a novel cannabimimetic, by gas chromatography-mass spectrometry. Drug Test Anal. 2012; 4: 519-24.

63. Kacinko SL, Xu A, Homan JW, et al. Development and validation of a liquid chromatography-tandem mass spectrometry method for the identification and quantification of JWH-018, JWH-073, JWH-019, and JWH-250 in human whole blood. J Anal Toxicol. 2011; 35: 386-93.

64. Logan BK, Reinhold LE, Kacinko SL. K2 and Beyond: A Synthetic Cannabinoid Primer (K43). American Academy of Forensic Sciences; Chicago, IL: 2011

65. Teske J, Weller JP, Fieguth A, et al. Sensitive and rapid quantification of the cannabinoid receptor agonist naphthalen-1-yl-(1-pentylindol-3-yl) methanone (JWH-018) in human serum by liquid chromatography-tandem mass spectrometry. J Chromatogr B Analyt Technol Biomed Life Sci. 2010; 878: 2659-63.

66. Toennes SW, Geraths A, Pogoda W, et al. Pharmacokinetic properties of the synthetic cannabinoid JWH-018 and of its metabolites in serum after inhalation. J Pharm Biomed Anal. 2017; 140: 215-222.

67. Theunissen EL, Hutten NRPW, Mason NL, et al. Neurocognition and subjective experience following acute doses of the synthetic cannabinoid JWH-018: a phase 1, placebo-controlled, pilot study. Br J Pharmacol. 2018; 175: 18-28.

68. Gaoni Y, Mechoulam R. Isolation, Structure, and Partial Synthesis of an Active Constituent of Hashish. J. Am. Chem. Soc. 1964; 86: 1646-7.

69. Agencia Española del Medicamento y Productos Sanitarios (AEMPS). Nota informativa de la AEMPS sobre Rimonabant (Acomplia®). https://www.aemps.gob.es/informa/notasInformativas/medicamento sUsoHumano/seguridad/2009/NI_2008-18.htm

70. Food and Drug Administration (FDA). Drugs. http://www.fda.gov/

71. Agencia Española del Medicamento y Productos Sanitarios (AEMPS). https://www.aemps.gob.es/

72. European Medicine Agency (EMA). Recuperado de http:// www.ema.europa.eu/ema/

73. Klumpers LE, Beumer TL, van Hasselt JG, et al. Novel $\Delta(9)$ -tetrahydrocannabinol formulation Namisol ${ }^{\circledR}$ has beneficial pharmacokinetics and promising pharmacodynamic effects. Br J Clin Pharmacol. 2012; 74:42-53.

74. Echo Pharmaceuticals BV. http://www.echo-pharma.com/en/

75. Gofshteyn JS, Wilfong A, Devinsky O, et al. Cannabidiol as a Potential Treatment for Febrile Infection-Related Epilepsy Syndrome (FIRES) in the Acute and Chronic Phases. J Child Neurol. 2017; 32: 35-40.

76. GH Pharmaceuticals. https://www.gwpharm.com/

77. Clinicaltrials.gov. U.S. National Library of Medicine. https:// clinicaltrials.gov/ct2/home

78. Hashim PW, Cohen JL, Pompei DT, et al. Topical cannabinoids in dermatology. Cutis. 2017 Jul;100(1):50-52.

79. Law R, Schier J, Martin C, et al. Notes from the Field: Increase in Reported Adverse Health Effects Related to Synthetic Cannabinoid Use United States, January-May 2015. MMWR Morb Mortal Wkly Rep. 2015; 64: 618-9.

80. Courts J, Maskill V, Gray A, et al. Signs and symptoms associated with synthetic cannabinoid toxicity: systematic review. Australas Psychiatry. 2016; 24: 598-601.

81. Tait RJ, Caldicott D, Mountain D, et al. A systematic review of adverse events arising from the use of synthetic cannabinoids and their associated treatment. Clin Toxicol (Phila). 2016; 54:1-13.

82. Tournebize J, Gibaja V, Kahn JP. Acute effects of synthetic cannabinoids: Update 2015. Subst Abus. 2017; 38: 344-366.

83. Waugh J, Najafi J, Hawkins L, et al. Epidemiology and clinical features of toxicity following recreational use of synthetic cannabinoid receptor agonists: a report from the United Kingdom National Poisons Information Service. Clin Toxicol (Phila). 2016; 54: 512-8.

84. D'Souza DC, Radhakrishnan $\mathrm{R}$, Sherif $\mathrm{M}$, et al. Cannabinoids and Psychosis. Curr Pharm Des. 2016; 22: 6380-91.

85. van Amsterdam J, Brunt T, van den Brink W. The adverse health effects of synthetic cannabinoids with emphasis on psychosis-like effects. J Psychopharmacol. 2015; 29: 254-63.

86. Cohen K, Weinstein A. The Effects of Cannabinoids on Executive Functions: Evidence from Cannabis and Synthetic Cannabinoids-A Systematic Review. Brain Sci. 2018; 8: E40.

87. Adams AJ, Banister SD, Irizarry L, et al. "Zombie" Outbreak Caused by the Synthetic Cannabinoid AMB-FUBINACA in New York. N Engl J Med. 2017; 376: 235-242.

88. Global Drug Survey 2016. https://www.globaldrugsurvey.com/

89. Freeman TP, Winstock AR. Examining the profile of high-potency cannabis and its association with severity of cannabis dependence. Psychol Med. 2015; 45: 3181-9.

90. Winstock A, Lynskey M, Borschmann R, et al. Risk of emergency medical treatment following consumption of cannabis or synthetic cannabinoids in a large global sample. J Psychopharmacol. 2015 Jun;29(6):698-703. 
91. Adamowicz P. Fatal intoxication with synthetic cannabinoid MDMB-CHMICA. Forensic Sci Int. 2016; 261:e5-10.

92. Bäckberg M, Tworek L, Beck O, Helander A. Analytically Confirmed Intoxications Involving MDMB-CHMICA from the STRIDA Project. J Med Toxicol. 2017; 13: 52-60.

93. Hill SL, Najafi J, Dunn M, et al. Clinical toxicity following analytically confirmed use of the synthetic cannabinoid receptor agonist MDMB-CHMICA. A report from the Identification Of Novel psychoActive substances (IONA) study. Clin Toxicol (Phila). 2016; 54: 638-43.

94. Meyyappan C, Ford L, Vale A. Poisoning due to MDMB-CHMICA, a synthetic cannabinoid receptor agonist. Clin Toxicol (Phila). 2017; 55: 151-152.

95. Seywright A, Torrance HJ, Wylie FM, et al. Analysis and clinical findings of cases positive for the novel synthetic cannabinoid receptor agonist MDMB-CHMICA. Clin Toxicol (Phila). 2016; 54: 632-7.

96. Westin AA, Frost J, Brede WR, et al. Sudden Cardiac Death Following Use of the Synthetic Cannabinoid MDMB-CHMICA. J Anal Toxicol. 2016; 40: 86-7.

97. Kerbrat A, Ferré JC, Fillatre P, et al. Acute Neurologic Disorder from an Inhibitor of Fatty Acid Amide Hydrolase. N Engl J Med. 2016; 375: 1717-1725.

98. Kaur R, Sidhu P, Singh S. What failed BIA 10-2474 Phase I clinical trial? Global speculations and recommendations for future Phase I trials. J Pharmacol Pharmacother. 2016; 7: 120-6.

99. Moore N. Lessons from the fatal French study BIA-10-2474. BMJ. 2016; 353:i2727.

100. Tong J, Mizrahi R, Houle S, et al. Inhibition of fatty acid amide hydrolase by BIA 10-2474 in rat brain. J Cereb Blood Flow Metab. 2017; 37: 3635-3639.

101. van Esbroeck ACM, Janssen APA, Cognetta AB 3rd, et al. Activity-based protein profiling reveals off-target proteins of the FAAH inhibitor BIA 10-2474. Science. 2017; 356: 1084-1087.

102. Food and Drug Administration (FDA). FDA finds drugs under investigation in the U.S. related to French BIA 10-2474 drug do not pose similar safety risks. https://www.fda.gov/Drugs/DrugSafety/ ucm482740.htm 